Artículos

\title{
Abordaje arqueológico del sitio Casa Natal Sarmiento (San Juan, Argentina) como caso de arquitectura colonial doméstica
}

\author{
Archaeological approach to the Casa Natal Sarmiento \\ site (San Juan, Argentina) as a case of domestic colonial \\ architecture
}

Igareta*, Ana; Chechi**, Florencia

\author{
Ana Igareta* \\ aigareta@gmail.com \\ Historia, Teoría y Praxis de la Arquitectura y la \\ Ciudad. Instituto de Investigación. Facultad de \\ Arquitectura y Urbanismo. Universidad Nacional de \\ La Plata., Argentina \\ Florencia Chechi** \\ fmchechi@hotmail.com \\ Historia, Teoría y Praxis de la Arquitectura y la \\ Ciudad. Instituto de Investigación. Facultad de \\ Arquitectura y Urbanismo. Universidad Nacional de \\ La Plata., Argentina
}

Estudios del Hábitat

Universidad Nacional de La Plata, Argentina

ISSN: 2422-6483

Periodicidad: Semestral

vol. 18 , núm. 2,2020

aefau@fau.unlp.edu.ar

Recepción: 02 Junio 2020

Aprobación: 18 Noviembre 2020

Publicación: 30 Diciembre 2020

URL: http://portal.amelica.org/ameli/ jatsRepo/158/1581621003/index.html

\section{c) (7) $\Theta$}

Esta obra está bajo una Licencia Creative Commons AtribuciónNoComercial-SinDerivar 4.0 Internacional.
Resumen: El edificio del Museo y Biblioteca Casa Natal de Sarmiento es uno de los pocos ejemplares de arquitectura doméstica colonial que aún permanecen en pie en la ciudad de San Juan (San Juan, Argentina). Si bien por más de dos siglos ha sufrido modificaciones y adiciones, conserva el núcleo arquitectónico construido a comienzos del siglo XIX, por lo que su estudio y el del sitio en que se encuentra como conjunto integrado podrían aportar datos significativos a la comprensión del proceso de ocupación doméstica de la ciudad a fines del periodo colonial. El presente trabajo, un análisis arqueológico de fuentes históricas, tuvo como objetivo la reconstrucción del contexto físico en que se dio la ocupación y construcción de la vivienda, y la identificación de los principales rasgos materiales que se articularon en dicho proceso.

Palabras clave: San Juan (Argentina), proceso de ocupación del sitio, casa natal Sarmiento, arqueología colonial.

Abstract: The Museo y Biblioteca Casa Natal de Sarmiento building is one of the few examples of colonial domestic architecture that still stands today in the city of San Juan (San Juan, Argentina). Although it has undergone modifications and additions for more than two centuries, it preserves the architectural nucleus built in the early nineteenth century, so that its study could contribute significant data to the understanding of the process of domestic occupation of a city plot at the end of the colonial period. The objective of this work was the archaeological reconstruction of the physical context of the site where the occupation took place and the construction of the house began, the characterization of the space in which it was developed and the estimation of how it was articulated with other features of the urban landscape then defined.

Keywords: San Juan (Argentina), site occupation process, colonial archeology, casa Natal Sarmiento. 


\section{CONSIDERACIONES GENERALES}

$\mathrm{Al}$ igual que en otras ciudades fundadas en Cuyo y el antiguo Tucumán durante el siglo XVI, el actual casco urbano de San Juan conserva escasos ejemplos de arquitectura doméstica colonial. Un reciente relevamiento arqueológico solo localizó seis edificios cuya construcción podría remontarse al periodo colonial y ninguno de ellos es anterior a la segunda mitad del siglo XVIII. Tal escasez parece ser el resultado de la combinación de procesos de transformación propios de cualquier ámbito urbano, malas políticas de conservación patrimonial y sucesivas inundaciones y terremotos que afectaron la ciudad a lo largo de los cinco siglos (Sentagne et al. 2010). No hay publicaciones que evidencien que los edificios conservados hayan sido hasta ahora objeto de un análisis sistemático de ningún tipo, así como tampoco se han desarrollado en la ciudad proyectos de arqueología urbana que pudieran recuperar evidencia material enterrada, lo que implica que la información disponible de primera mano sobre la materialidad de la arquitectura colonial de la ciudad es extremadamente escasa. Sí se dispone de análisis históricos que han proporcionado descripciones más o menos detalladas de las viviendas de la primitiva San Juan, pero son contados los autores que explicitan las fuentes de las que obtuvieron sus datos, lo que obliga a considerar tales descripciones con cautela.

Entre las construcciones domésticas conservadas se incluye el edificio en el que hoy funciona el Museo y Biblioteca Casa Natal de Domingo Faustino Sarmiento (MBCNS), ubicado en la intersección de las calles Domingo F. Sarmiento Sur y Av. Libertador Gral. San Martin Oeste y declarado Monumento Histórico Nacional en 1910 por ley $\mathrm{N}^{\circ} 7062$ (Figura 1 y Figura 2). De acuerdo al reconocimiento, la casa había sido edificada por encargo de Paula Albarracín una década antes del nacimiento de Sarmiento pero, como era habitual en la época, la declaratoria estuvo basada exclusivamente en referencias orales y datos documentales. No hay evidencias de que al momento de su patrimonialización o al convertirse en museo un año después, las características el edificio hayan sido relevadas o estudiadas. El texto de la ley indicaba que "... la casa es un edificio modestisimo, que no se ha modificado, sea porque sus herederos han sido y son pobres, o bien han querido conservar intacto este humilde hogar...”. Teniendo en cuenta que Sarmiento nació en 1811 y que desde entonces la construcción fue intervenida, ampliada y reformada en respuesta a las cambiantes necesidades de uso de su familia, estimamos que la propuesta de que un siglo después su materialidad no se hallaba modificada resulta poética pero poco ajustada a la realidad (Igareta et al. 2020).

Durante la primera mitad del siglo XX el edificio fue objeto de nuevas intervenciones, incluyendo una agresiva reconstrucción luego del terremoto de 1944 y una ampliación a fines de la década de 1950 (De Masi 2011) que le otorgaron su fisonomía actual. Sin embargo, un reciente análisis de su historia constructiva estableció que el conjunto murario de la pequeña vivienda original permanece en pie, articulada con secciones más modernas pero con sus rasgos conservados (Plana 2013), lo que la convierte en uno de los pocos casos de arquitectura doméstica del periodo colonial tardío conocidos en toda la ciudad.

En el marco de una investigación arqueológica más amplia, este trabajo tuvo como objetivo analizar desde la evidencia documental el proceso de ocupación del sitio, intentar definir el contexto físico en que se instaló la vivienda y cómo éste se vio transformado por dicha instalación. Identificamos el lapso que va desde el año 1801 hasta 1810 como el periodo inicial de ocupación del sitio y en el que se centra nuestro interés, dado que a partir de entonces su materialidad se vio drásticamente transformada. Cabe mencionar que si bien la vinculación de la casa con la figura de Sarmiento fue, en gran medida, el motivo de su preservación hasta la actualidad, el presente análisis se orienta a la reconstrucción de la dinámica de ocupación de un espacio doméstico y que es el sitio arqueológico -y no el personaje histórico ni el edificio en sí mismo- el centro de la indagación. El trabajo buscó analizar y organizar la información histórica disponible sobre los procesos domésticos que impactaron materialmente en el sitio generando un correlato material singular susceptible de ser recuperado por una intervención estratigráfica directa. 


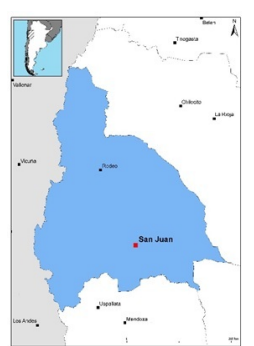

FIGURA 1

UBICACIÓN DE LA CIUDAD DE SAN JUAN EN LA PROVINCIA DE IGUAL NOMBRE FUENTE: ELABORACIÓN DE DIEGO GOBBO, (DIVISIÓN ARQUEOLOGÍA, MUSEO DE LA PLATA, UNLP) A PARTIR DE DATOS SIG VECTORIALES DE LA CONAE (2020).

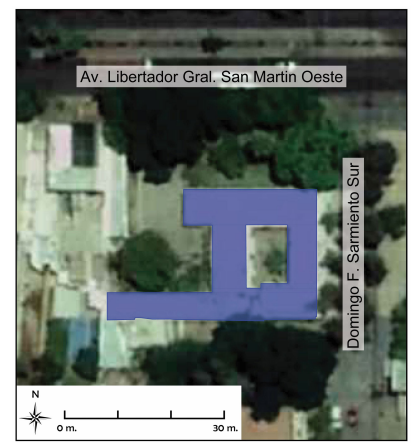

FIGURA 2

VISTA AÉREA DEL EDIFICIO ACTUAL DEL MUSEO Y BIBLIOTECA SARMIENTO FUENTE: GRÁFICO Y MONTAJE ARQ. CHECHI, F.

\section{MARCO DE REFERENCIA}

A diferencia de lo que ocurre en otro tipo de sitios en los que el paisaje actual no difiere significativamente del arqueológico, los sitios urbanos se ven afectados de modo casi ineludible por transformaciones drásticas que los destruyen, alteran al extremo sus características originales o que, en el mejor de los casos, los sepultan bajo capas de ladrillo y hormigón (Schávelzon 2019). Ello obliga a los arqueólogos a excavar en los pequeños sectores de la superficie que permanecen sin construir y a atravesar pisos, contrapisos, cimientos y cañerías hasta alcanzar los niveles de interés. También a consultar y revisar exhaustivamente fuentes históricas, gráficas y escritas, para destilar de los documentos fragmentos de evidencia que expliquen la materialidad de nuestro interés. Pero, sobre todo, hacer arqueología urbana significa investigar un paisaje arqueológico definido y dominado por el registro construido, ya sea que siga en pie o no cuando nos ocupemos de él.

Taboada define el campo de trabajo de la "Arqueología de la Arquitectura" como el estudio del ambiente construido y el modo cómo este influye en las relaciones sociales. Uno de sus intereses es "... definir prácticas constructivas y formas de uso del espacio habitacional como un medio de acceder a las conductas cotidianas, modos de vida y organización social de los grupos domésticos en relación a sus marcos históricos de referencia y a una dinámica mutuamente constituida." (Taboada 2016:4). Sin pretender que el presente sea un trabajo de Arqueología de la Arquitectura, es esa relación entre uso social y espacio construido la que buscamos explorar en el sitio que nos ocupa. Articulando las piezas de información proporcionadas por las fuentes documentales intentamos definir cuáles fueron los límites de ese espacio doméstico, cómo y a partir de qué recursos se planteó la ocupación y de qué modo la construcción de la vivienda se materializó en el sitio y se convirtió en el eje articulador de las actividades cotidianas de sus ocupantes. 
Por tratarse de un análisis histórico, el trabajo se basó en la revisión de documentos del Archivo Histórico de la provincia de San Juan, Archivo Histórico Gnecco de San Juan y el Archivo General de la Nación, y de publicaciones y bibliografía especializada. Siguiendo la propuesta de Senatore, el análisis desarrollado se estructuró como una dialéctica permanente entre las fuentes consideradas, aplicándose alternativamente estrategias de complementación, confrontación, integración, tratamiento independiente y búsqueda de contradicciones, de acuerdo a las necesidades de cada instancia del trabajo (Senatore 2007). La indagación continúa, pero debe destacarse que la información hasta hoy recuperada sobre los aspectos del sitio que nos ocupan fue extremadamente escasa, siendo "Recuerdos de provincia" de Sarmiento publicado por primera vez en 1850, el texto que más detalles proporcionó. Teniendo en cuenta que tanto ésta como otras memorias son relatos de individuos que no conocieron la casa durante el periodo analizado, y que en todos los casos describen lo relatado por terceros, los datos que brindan fueron utilizados con los correspondientes recaudos metodológicos. Pero dado que en muchas cuestiones particulares constituyen la única fuente histórica disponible, no fue posible evaluar su potencial informativo, tarea que recién podrá realizarse cuando se concrete en el sitio una intervención directa.

\section{EL TERRENO}

El análisis documental no permitió recuperar descripciones de la ciudad producidas durante el periodo colonial que mencionaran ejemplos de arquitectura doméstica ni fue posible localizar planos o gráficos de la ciudad de San Juan anteriores a mediados del siglo XIX que proporcionaran una perspectiva general del conjunto o de cómo se distribuía la población dentro de su casco urbano. De acuerdo a los datos históricos disponibles, a fines del siglo XVIII Paula Albarracín recibió en herencia de su padre un terreno ubicado "en el barrio del Carrascal, que se encuentra en un estremo de San Juan, i que en aquellos años era la morada de la parte mas pobre de la población" (Guerra Vallejos 1901:12) pero no fue posible hallar autores que brindaran más datos sobre sus límites o su población en la época. En tal sentido debemos mencionar que la propiedad de Albarracín se hallaba a $100 \mathrm{~m}$ de distancia del Convento de Santo Domingo y a menos de $500 \mathrm{~m}$ de la plaza mayor de la ciudad donde se ubicaban la Catedral, el Cabildo y las viviendas de los vecinos más poderosos (Figura 3). Ello podría indicar que la distancia que separaba a los habitantes del Carrascal del centro era más social que geográfica, o que incluso en momentos tan tardíos como comienzos del siglo XIX ${ }^{1}$ la ciudad contaba con una población tan escasa que unas pocas cuadras lejos de la plaza ya eran las afueras.

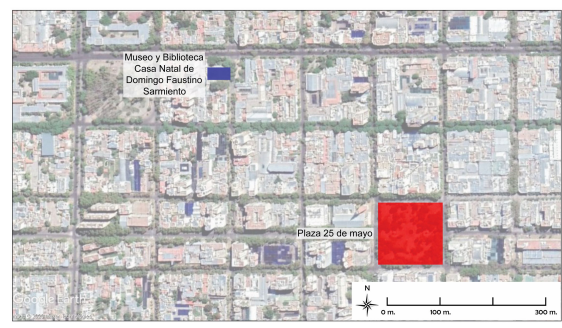

FIGURA 3

DETALLE DEL CASO URBANO ACTUAL DE SAN JUAN CON UBICACIÓN DEL SITIO EN AZUL Y EN ROJO LA PLAZA 25 DE MAYO (ANTIGUA PLAZA PRINCIPAL DE LA CIUDAD). FUENTE: GRÁFICO Y MONTAJE ARQ. CHECHI, F.

No localizamos aún escrituras, testamentería u otros documentos oficiales que den cuenta de las dimensiones de la propiedad heredada, que informen si al entrar en posesión de Albarracín era utilizada para algún tipo de actividad productiva o que indiquen si para entonces existía ya alguna construcción en su superficie. Solo es posible especular, tomando como referencia la información registrada en otros documentos de la época (Gray de Cerdán 1971) que aún se hallaba vigente en San Juan el modelo colonial de reparto 
de manzanas en cuatro solares y que, dada la ubicación de la casa, el terreno podría haber correspondido al ubicado en el cuadrante noreste de su manzana hoy definida por Av. Libertador Gral. San Martín Oeste, Domingo F. Sarmiento Sur, Francisco N. Laprida Oeste y Catamarca sur. Asumiendo que las dimensiones de las manzanas de la ciudad se mantuvieron constantes desde entonces -los registros de catastro no muestran cambios en los últimos 150 años en las de ese sector de la ciudad-habría tenido una superficie estimada de $125 \mathrm{~m}$ por $115^{2} \mathrm{~m}$ o 145 por 133 varas $^{3}$ y cada uno de los cuatro solares en que se dividía le corresponderían unas 72 por 67 varas de lado. Pero, como veremos luego, la superficie de ocupación efectiva de los lotes habría sido menor por la presencia de una acequia que atravesaba la manzana (Figura 4).

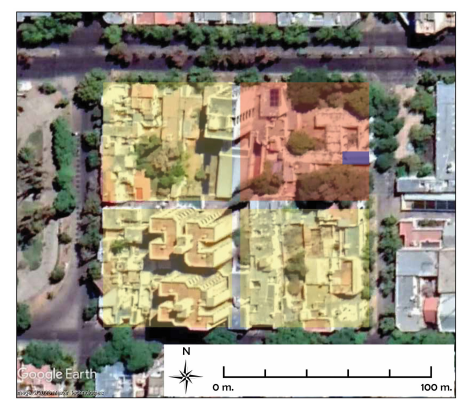

FIGURA 4

PROYECCIÓN DE LA UBICACIÓN DE LOS CUATRO SOLARES EN QUE HABRÍA ESTADO DIVIDIDA LA MANZANA EN LA QUE SE ENCUENTRA EL TERRENO HEREDADO POR ALBARRACÍN. EN AZUL LA POSICIÓN ACTUAL DE LA VIVIENDA CONSTRUIDA A COMIENZOS DEL SIGLO XIX. FUENTE: GRÁFICO Y MONTAJE ARQ. CHECHI, F.

El relato de Sarmiento sobre el terreno de su madre -único documento conocido que brinda un dato numérico en tal sentido- menciona "... sitio de treinta varas de frente por cuarenta de fondo ..." (Sarmiento [1850] 1927:116). Asumiendo que el recuerdo de Sarmiento es correcto al indicar que se trataba de una superficie menor a la de un cuarto de manzana, cabe especular que la propiedad podría haber correspondido a medio solar, de unas $67 \times 36$ varas o $73 \times 33$ varas, o a un tercio de solar, de $67 \times 24$ o $73 \times 22$ varas, de acuerdo a cómo se dispusieran las fracciones. Por supuesto que también sería posible que tuviera una superficie irregular, pero tomando como referencia la práctica más habitual de división de terrenos durante el periodo colonial, es plausible hipotetizar que sus dimensiones se aproximaron a alguna de las antes mencionadas.

Si bien no parece haber registros concretos sobre cómo se efectuó tal división, nos inclinamos por suponer que los lotes habían sido fraccionados en sentido norte-sur, a fin de asegurar que el fondo de todas las propiedades tuviera acceso a la acequia que corría por el centro de la manzana, en sentido oesteeste. En este punto resulta imprescindible recordar que las acequias urbanas fueron un rasgo particular de las ciudades de Cuyo desde momentos históricos tempranos ${ }^{4}$, dado que la extrema aridez de su geografía hacía imprescindible un sistema de provisión de agua para consumo y uso de los vecinos. Mientras que en otros centros urbanos del país el agua se obtenía directamente de los ríos o de pozos de balde excavados en los terrenos ocupados, en San Juan se desarrolló un sistema de canales que aprovechaba la pendiente y transportaba el agua que tomaba del Estero del Zonda (Roitman 1996) y que terminaba en un gran desagüe perpendicular, ubicado al este (Miranda 2015). 1 Se ha comprobado arqueológicamente que al momento de fundarse San Juan existía ya en la región una infraestructura hidráulica de acequias y canales prehispánicos, y se ha estimado que la instalación ibérica aprovechó tal sistema para el desarrollo de la nueva ciudad (Damiani y García 2011).

Hasta mediados del siglo XIX, "Por un lomo que partia por mitad las manzanas, corrian de oeste a este nueve acequias tocando los fondos de las casas para riego de la huerta familiar ..."(Videla 1956:57), y trabajos previos han estimado que una de ellas discurría por la línea de manzanas en que se ubicaba el lote de Albarracín (Roitman op. cit.). Curiosamente ninguno de los documentos consultados que se refiere a esta propiedad 
en particular menciona su existencia, si bien abundan las referencias a las "... viejas acequias coloniales que cruzaban por los fondos de las casas"(Gray de Cerdán 1971:27) y las caracterizaciones históricas que proponen una ineludible articulación de casa al frente y huerta/acequia al fondo.

No fue posible hallar hasta ahora una sola referencia escrita al ancho o profundidad de las acequias urbanas de San Juan a fines del siglo XVIII o comienzos del XIX así como tampoco menciones que indiquen si se trataba solo de un rasgo excavado en la tierra o si se hallaban recubiertas con piedras u otro material ${ }^{5}$. Larraín menciona que en el año 1818 y como parte de los esfuerzos de regularización del sistema local de distribución de agua se construyó una acequia para irrigar la región de Pocito, ubicada al suroeste de la ciudad de San Juan, que sirvió luego como modelo para las de los demás departamentos de la provincia. Tal acequia debía tener ".... desde su origen la anchura de cinco varas hasta la distancia de legua y media y de alli para adelante cuatro varas, teniendo el fondo de una vara de agua..." (Larraín 1906:370). Aunque el dato no corresponde exactamente en tiempo ni espacio al proceso y al terreno que nos ocupa, consideramos pertinente incluirlo como referencia general dado que se trata de la única referencia registrada que brinda datos numéricos de las dimensiones de acequias de la región.

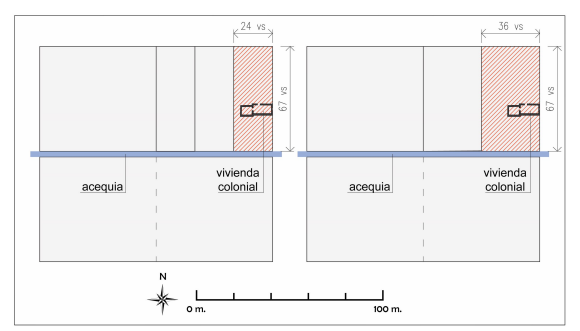

FIGURA 5

ESQUEMA QUE REPRESENTA LAS POSIBLES DIVISIONES DEL TERRENO HEREDADO

POR ALBARRACÍN COMO UN TERCIO (IZQUIERDA) O MEDIO (DERECHA) CUARTO DE

MANZANA Y LA POSICIÓN RELATIVA DE LA VIVIENDA CUYOS RESTOS AÚN SE CONSERVAN. FUENTE: DIBUJOS CHECHI, FLORENCIA.

Si bien como señalamos no hay referencias directas a una acequia en las inmediaciones del terreno que nos ocupa, la presencia de árboles frutales al momento de la instalación de Albarracín funciona como evidencia indirecta de su cercanía. Sarmiento indica que durante el tiempo que duró la construcción de la casa, su madre trabajó “...debajo de una de las higueras que habia quedado en su sitio..."(Sarmiento [1850] 1927:172). La higuera (Ficus carica L.) es un árbol de origen asiático cuya reproducción en territorio americano se realiza artificialmente por esquejes, dado que el insecto responsable de su reproducción en estado natural no se encuentra presente (Catraro 2014:5) ${ }^{6}$. Tolera sin problemas los suelos rocosos y la escasez de agua, pero requiere de mínimas provisiones de ésta a intervalos regulares para sobrevivir; por otra parte, si bien su crecimiento es relativamente rápido, son necesarios varios años para que este tipo de árboles alcance altura suficiente como para dar sombra. Luego, la presencia de higueras en el sitio antes del inicio de la construcción de la casa (particularmente de suficientes ejemplares como para que algunos fueran retirados y otros permanecieran para dar sombra) da cuenta de un uso previo intencional del terreno como espacio de cultivo, tal vez para cosechar sus frutos, ya fuera por parte de la familia Albarracín o de cualquier vecino, desde varios años antes.

\section{LA CASA}

No hay datos oficiales sobre en qué año exacto Albarracín inició la construcción de su vivienda o en qué parte del terreno la instaló, ya que no se han localizado documentos de catastro que lo indiquen. Diversos autores han estimado que la edificación se inició en el año 1801 a partir de los 23 años que Sarmiento menciona tenía 
entonces su madre. Y De Masi señala que la obra demoró un año en total en completarse (De Masi 2011:18), pero sin brindar detalles de la fuente de la que recupera dicha información. Sarmiento indica que la casa se ubicó "Hacia la parte del sur del sitio" (Sarmiento [1850] 1927:116), que la puerta de entrada se orientó hacia el norte y que por detrás de la casa quedaban veinte varas de terreno libre (Sarmiento [1850] 1927:180) descripción que coincide en términos generales con la ubicación y orientación del conjunto murario más antiguo que corresponde a la esquina sureste del edificio actual. Su relato parece sugerir que el frente de la propiedad se encontraba orientado hacia el norte, actual calle Libertador, mientras que el fondo se extendía hacia el sur, hasta la acequia, aunque dado que en ningún momento señala la presencia de tapias o cercado que limitara el espacio de la misma, puede suponerse que la gente accedía al terreno por el punto que le resultaba más conveniente.

Ninguna de las fuentes relevadas menciona la existencia de construcciones en el terreno al momento de ser heredado por su madre, y Sarmiento indica que la pobre herencia de su abuelo solo había consistido en terrenos despoblados (Sarmiento [1850] 1927:171), lo que permite asumir que la vivienda edificada a pedido de Albarracín fue la primera en ese lote. La mano de obra que llevó adelante la construcción se hallaba integrada por "... dos esclavos de sus tías Irrazabales [de Paula]... peones y maestros..." (Sarmiento [1850] 1927:172); el uso del plural en el segundo conjunto permite estimar la participación de al menos 6 individuos en la tarea. No nos detendremos en esta oportunidad en analizar el origen étnico de los constructores, resulta interesante la mención de esclavos que se desempeñan como albañiles, ya que se trata de un tema escasamente abordado a nivel regional (mucho más analizada está su labor como carpinteros) ${ }^{7}$. Sí destacaremos la referencia a maestros, ya que sería indicativa de que al menos dos de los individuos involucrados en la construcción contaban con experiencia en la actividad, lo que sin dudas influyó en el resultado final, generando un objeto construido de características bien diferentes al que hubiera resultado de la labor de constructores inexpertos.

No detectamos un solo dato en fuentes contemporáneas al momento de la edificación que refieran al sistema o materias primas con que se hicieron sus cimientos, techo o carpinterías. Con respecto a estas últimas los escritos tampoco mencionan si la casa tenía o no ventanas o dónde se ubicaban, y la única alusión a la presencia de aberturas en el texto de Sarmiento es la mención de la puerta de acceso que se abría hacia el norte. Por su parte, la única mención conocida al solado de la edificación colonial es un recuerdo de una sobrina de Sarmiento quien, en 1919, afirmó en referencia a la habitación más antigua: "Esta pieza como toda la casa, tenía el piso de tierra apisonada..." (transcripto en Erostarbe 2004:29). Tal falta de datos de primera mano obliga a preguntarse de dónde proviene la información utilizada por autores que describieron la casa, proporcionando detalles tales como "... construcción cuadrilonga de adobe y tejado en capucha, con sus ventanitas trepadas á los muros de cabecera ...” (Lugones 1910:33); “... construcción de adobe con piso de ladrillo y techos de caña y barro..." (Guerrero 1963 citado por De Masi 2011:17).

En cambio sí se dispone de datos sobre la materia prima empleada en los muros, iniciando con la mención de "adobes y tapias" realizada por el propio (Sarmiento [1850] 1927:116). Si bien ambos sistemas se basan en la utilización de tierra cruda, el uso del espacio para la preparación de los materiales y los tiempos de realización de la obra habrían sido significativamente diferentes en caso de utilizarse un encofrado o bloques de adobe -ya fueran transportados hasta el sitio o manufacturados allí-, y las características de los paramentos resultantes también serían diferentes. Como mencionamos, no se ha realizado hasta hoy una exploración directa de los muros cuyos resultados proporcionarían datos concretos en uno u otro sentido por lo que una consideración minuciosa obliga a estimar varias posibilidades, incluyendo que uno de los sistemas fuera utilizado en algunas de las paredes y otro en las restantes (poco probable); que uno se empleara en los muros perimetrales y otro en divisiones internas, o que uno fuera usado en todos los muros de la vivienda y otro en un tapial que rodeara el terreno (y cuya existencia no fuera señalada por ninguna de las fuentes relevadas). Estudios previos han comprobado un uso recurrente en San Juan hasta entrado el siglo XIX de tapias con 
cimientos de piedra para cerrar propiedades y subdividir patios y huertos, incluso en unidades domésticas de apenas 10 o 20 varas de extensión (Lacoste et al. 2012:188).

El análisis de fotografías de la casa obtenidas luego del terremoto de 1944 permitió observar cómo en al menos uno de los muros construidos a mediados del siglo XIX se utilizaron mampuestos individuales, aunque en las ocho imágenes revisadas las paredes de la sección colonial se encuentran total o parcialmente cubiertas por revoque, lo que hizo imposible una observación semejante. Es posible que la vista de dichos adobes llevara a quienes se interesaron por la historia de la casa a suponer que el mismo material y sistema constructivo había sido utilizado en todos sus muros (Figura 6). Por otra parte, en los informes generados tanto por Mario Buschiazzo (Casa de Sarmiento, Legajo no 1, Archivo CNMMyLH) como por Vicente Nadal Mora (1957) para la Comisión Nacional de Museos, Monumentos y Lugares Históricos a posteriori del terremoto, ambos nombran colectivamente los paramentos históricos del edificio como "muros de adobe"; teniendo en cuenta que, según su propio relato, gran parte del revoque interno de las habitaciones había caído, cabe la posibilidad de que ellos tuvieran una vista directa de la técnica constructiva del conjunto murario colonial (aunque en ninguna instancia explicitan nada al respecto).

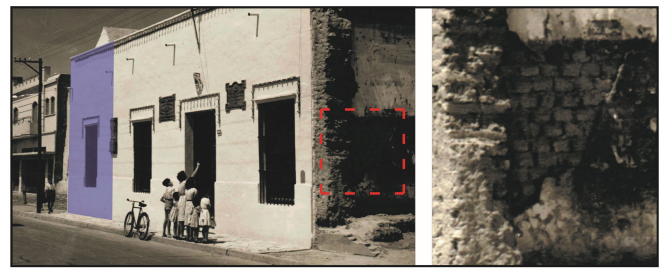

FIGURA 6

FOTOGRAFÍA DEL EDIFICIO TOMADAS LUEGO DEL TERREMOTO DE 1944: EN AZUL, LA SECCIÓN QUE CORRESPONDE A LA CONSTRUCCIÓN COLONIAL Y RECUADRADO EN ROJO Y AMPLIADO,

DETALLE DEL MURO NORTE QUE PERMITE OBSERVAR LA UTILIZACIÓN DE LADRILLONES DE ADOBE. FUENTE: FOTOGRAFÍA PUBLICADA EN LA PÁGINA DEL MINISTERIO DE CULTURA, ARGENTINA Y REPRODUCIDA EN HTTPS://WWW.CULTURA.GOB.AR/107-ANIVERSARIO-DEL-MUSE O-Y-BIBLIOTECA-CASA-NATAL-DE-SARMIENTO_5569/.COLOREADO ARQ. CHECHI, F.

Las fuentes revisadas no refieren si los muros de la vivienda fueron cubiertos con revoque una vez terminada la construcción, y solo es posible especular que sí dado que el uso de "paredes revocadas con barro y pintadas a la cal"fue una constante en la arquitectura colonial de la ciudad (Gil 1948:124). En lo que respecta al color de su superficie, al referirse a cambios ocurridos en la casa entre las décadas de 1810 y 1820, Sarmiento detalla que "Las murallas de la común habitación fueron aseadas y blanqueadas de nuevo," (Sarmiento [1850] 1927:187) lo que indicaría que su superficie había sido blanqueada ya al menos en una ocasión anterior, aunque resulta imposible establecer cuándo o con qué frecuencia se repetía tal acción.

De acuerdo al relato de Sarmiento toda la construcción original se limitaba a una "... habitación única de la casa, dividida en dos departamentos"(Sarmiento [1850] 1927:116) con una puerta de acceso que se abría hacia el norte. La alusión a un único ambiente dividido podría indicar el uso de un elemento divisorio no estructural tipo cortinado como hacer referencia a un tabique o muro interno; sin más datos resulta imposible precisarlo. Como dijimos, el conjunto colonial conforma la esquina sureste del edificio actual, y la mayor parte de los autores han estimado que solo la habitación ubicada en el extremo de dicha esquina es la más antigua y que la división mencionada por Sarmiento no se conservó (Lenoir de Klappenbach 1919 citado en Erostarbe 2004; Belín de Sarmiento 1949; Plana 2013). Sin embargo, también debe considerarse la posibilidad de que dicha mención a dos departamentos refiera a la habitación de la esquina y la que se articula linealmente con ella hacia el oeste, y que el muro que las conecta conformara la nombrada división. En el primer caso -tomando como referencia las dimensiones actuales de las habitaciones- la superficie interna de la vivienda habría sido de unos $40 \mathrm{~m}^{2}$, mientras que en el segundo, de $68 \mathrm{~m}^{2}$. 
Desde el año $1922^{8}$ en los planos del edificio se indica, en la cara externa del muro sur, un quiebre y un cambio de espesor entre ambas habitaciones que se observa en la construcción actual; tal discontinuidad podría evidenciar que solo el recinto de la esquina sureste conforma el núcleo arquitectónico más antiguo y que el otro fue construido en una etapa posterior, aunque a partir de los documentos resulta imposible estimar cuánto tiempo más tarde. Por otra parte, en el plano más antiguo que se conoce de la propiedad, un gráfico del año 1862 incluido en el expediente de la sucesión de José Sarmiento y Paula Albarracín de Sarmiento (cuyo original se conserva en el archivo del Museo) la casa aparece dibujada como era entonces y la imagen no registra ninguna discontinuidad entre ambas habitaciones, lo que podría indicar que ésta es el resultado de un proceso de transformación ocurrido a posteriori. Una tercera posibilidad es que la discontinuidad ya estuviera presente en 1862 pero que el dibujante simplificara el diseño obviando algunos detalles; como dijimos, las fuentes escritas no proporcionan datos que permitan precisar qué hipótesis se ajusta más a explicar la materialidad del edificio..

\section{OTROS RASGOS}

La ocupación efectiva de terreno por parte de la familia de Albarracín implicó, además de la construcción de la casa, la implementación de un conjunto de prácticas domésticas que generaron su propio registro material. Entre ellas, la preparación de comida; los escritos dan cuenta de la presencia de árboles frutales y una pequeña huerta en la propiedad pero ni una sola de las fuentes menciona cómo y dónde eran procesados esos y otros alimentos. Sarmiento menciona en su relato que Albarracín utilizaba dentro de la casa un brasero para calentar el agua del mate (Sarmiento [1850] 1927:188) pero no pudimos detectar datos sobre la ubicación y características de la cocina en el primitivo edificio. Los pocos textos de análisis histórico que mencionan el espacio de cocina de las viviendas coloniales sanjuaninas indican que ésta solía encontrarse "... en el segundo patio, junto a las habitaciones de servicio..." (Manzini 2011:175), dato poco relevante cuando las construcciones analizadas corresponden a viviendas de recursos más modestos cuya planta carecía de patios o de más de una habitación. Solo es posible considerar como posibilidades que la cocina se ubicara en alguna de las esquinas de la edificación primitiva; que se utilizara para tal fin algún tipo de pequeña construcción anexa de tierra cruda o materiales perecederos luego desaparecida o que las acciones de procesamiento y cocción se realizaran sencillamente en un fogón al aire libre que difícilmente generara ningún tipo de registro material perdurable.

Los documentos tampoco proporcionan información sobre la práctica de descarte de residuos domésticos de los ocupantes de la vivienda o la presencia de basureros en superficie, pozos de basura y/o excavados en el sitio. De hecho no pudimos localizar ni una sola referencia histórica del San Juan colonial en la que se mencionara el tratamiento dado a los residuos de cualquier tipo 9 . Pero cronistas y documentos oficiales indican que en Mendoza -la ciudad más poblada de Cuyo- era práctica habitual desde inicios del periodo colonial utilizar las mismas acequias con las que se regaban los huertos para arrojar basura y materia fecal, lo que llegó a convertirlas en el siglo XIX en cloacas a cielo abierto (Cirvini 1989:114). Dada las probadas semejanzas de las prácticas domésticas de los habitantes de ambas ciudades (Manzini 2011), es posible asumir que en San Juan se dio un uso similar a las acequias, aunque aún resta establecer de qué modo los residuos llegaban a ella. Las posibilidades a considerar incluyen que se los arrojara manualmente o que existiera algún tipo de pequeño drenaje excavado que los transportara desde algún punto más cercano a la casa; particularmente en lo que refiere al desagote de aguas servidas, puede estimarse que existiera algún tipo de mínima construcción de tierra cruda o material perecedero, externa a la vivienda y que fuera usado como “común” por sus ocupantes. 


\section{CONSIDERACIONES FINALES}

En el año 1834 el desborde del río San Juan inundó el casco urbano de la ciudad generando daños significativos a personas y propiedades; a consecuencia de la inundación, se construyó un dique e implementó un nuevo diseño de acequias que desdibujó de modo definitivo el aspecto colonial que la ciudad mantenía hasta entonces y la convirtió progresivamente en una urbe moderna (Sentagne et al. 2010). Como resultado, el origen colonial de la población es difícil de rastrear en su superficie actual, pero indudablemente su subsuelo alberga evidencia cuya recuperación permitirá una comprensión más acabada del devenir histórico de su materialidad durante los primeros 300 años de su existencia.

La reconstrucción de la dinámica de ocupación de cualquier ciudad requiere la paciente reconstrucción de los procesos de ocupación de los pequeños espacios domésticos donde se instalaron sus habitantes, del registro de los recursos materiales y criterios que utilizaron para hacerla efectiva y de la identificación de los actores sociales que la llevaron adelante. Requiere, también, del análisis minucioso y la articulación crítica de información provista por fuentes diversas para hacer posible la elaboración de modelos que sean luego puestos a prueba. El resultado obtenido durante un primer análisis del caso de Paula Albarracín permitió ahondar en aspectos particulares del proceso de ocupación de un sitio urbano a comienzos del siglo XIX por parte de una familia de modestos recursos, y recuperar y ordenar la información histórica disponible sobre la materialidad de dicho proceso. La indagación puso en evidencia la escasez de datos primarios sobre aspectos básicos de dicha ocupación y sobre el uso de su espacio doméstico, obligando a construir hipótesis que revisaran todas las posibilidades al respecto.

Pero generó a la vez un mapa de posibles marcadores físicos susceptibles de ser recuperados por una intervención arqueológica estratigráfica, y un corpus básico de información que colaborará en la interpretación de cualquier hallazgo material. Cabe esperar que la exploración directa del sitio y del edificio que nos ocupa, programada para la siguiente etapa de la investigación, proporcione datos de interés para el estudio de algunas de las problemáticas mencionadas. Para ello hemos diseñado un plan de trabajo que combina técnicas de la arqueología de la arquitectura y análisis arqueométricos con una intervención por encima y por debajo de cota cero que, esperamos, permitirá obtener precisiones sobre aspectos clave de la materialidad de la antigua construcción colonial y del uso de su espacio doméstico del terreno por parte de sus primeros ocupantes.

Por otra parte, el análisis desarrollado nos permitió identificar algunos conceptos relacionados con la vivienda doméstica colonial de la ciudad que no han sido estudiados sistemáticamente ni confrontados con otros corpus de evidencia, y que por ello mismo requieren de un análisis más cuidadoso. Por ejemplo, la noción de que la planta de las típicas casas coloniales sanjuaninas contaban con uno o dos zaguanes, locales comerciales al frente, dos o tres patios y huertos de hortalizas y frutales al fondo (e.g. Gil 1948:125). Si lo típico es aquello que se repite con mayor frecuencia en cierto contexto y, por ejemplo, el Primer Censo Nacional indica que para 1869 solo existían en San Juan 17 casas de dos cuerpos mientras que las restantes 1092 poseían uno (RA1869, Tomo II: 400), resulta imprescindible aceptar que la proliferación de habitaciones o la disponibilidad de dos zaguanes o dos patios era un rasgo limitado a unas pocas viviendas. No ponemos en duda la existencia de ejemplos de casas de varios cuerpos y ambientes, pero sus características parecen corresponder a la vivienda de los pocos vecinos más acomodados, mientras que la población urbana más numerosa eran vecinos de menores recursos cuyas casas probablemente se asemejaban más a la de Albarracín. Estimamos que será de interés un análisis que revise el grado de representatividad de un modelo con una única "casa típica" y plantee, en cambio, la necesidad de elaborar modelos que den cuenta de distintas materialidades típicas.

Igualmente relevante resultará sin duda la exploración arqueológica de la articulación espacial y funcional que se dio entre viviendas y acequias, ya sea en el caso de la propiedad de Albarracín como en cualquier otro ejemplo contemporáneo de características semejantes que pudiera ser identificado, dado que se trata de un 
aspecto de la vida doméstica del San Juan colonial del que las fuentes escritas virtualmente no ofrecen datos pero que sin duda influyó de modo significativo en su historia urbana.

\section{Agradecimientos}

A María Julia Gnecco y personal del Museo Gnecco de San Juan y a María Rosa Plana y personal del Museo y Biblioteca Casa Natal de Sarmiento por su colaboración en la consulta documental y bibliográfica. A Emilia Erostarbe por su confianza.

\section{REFERENCIAS}

Belín de Sarmiento, E. (1949). Croquis de casa de Sarmiento en San Juan, Buenos Aires junio 10 - 1949. Original realizado a mano alzada en guarda en el Museo Histórico Sarmiento, Buenos Aires.

Catraro, M. (2014). El cultivo de la higuera: Producción de higos y su deshidratación como método para el agregado de valor del producto. [Trabajo Final para optar al grado académico de Especialista en Cultivos Intensivos. Facultad de Ciencias Agrarias.Universidad Nacional del Litoral.]

Cirvini, S. (1989). El ambiente urbano en Mendoza a fines del siglo XIX. La higiene social como herramienta del proyecto utópico del orden. En Cerutti Guldberg, H. \& Rodríguez Lapuente, M. (comps.), Arturo Andrés Roig:Filósofo e Historiador de las Ideas (pp.113-140), Universidad de Guadalajara.

Damiani, Ó. \& García, A. (2011). El manejo indígena del agua en San Juan (Argentina): diseño y funcionamiento del sistema de canales de Zonda. Multequina, 20, 27-42

De Massi, O. (2011). Cuatro moradas sarmientinas con declaratoria nacional. Eustylos.

\section{REFERENCIAS}

Erostarbe, J. (2004). Casa natal de D. F. Sarmiento. Mirar fundando una nueva mirada. Universidad Nacional de San Juan. Facultad de Filosofía, Humanidades y Artes.

Gil, O (1948). Tradiciones sanjuaninas. Péuser.

Gray de Cerdán, N. (1971). La ciudad de San Juan. Su influencia regional y su proyección en la red de ciudades de Cuyo. Boletín de Estudios Geográficos, 18, (70-73), 7-245.

Guerra Vallejos, J. G. (1901). Sarmiento. Su vida i sus obras. Imprenta Elzeviriana

Igareta, A. \& Chechi, F. (2020). Arquitectura bajo cota cero: pozos y poceros de Buenos Aires en los siglos XVIII y XIX. Comechingonia. Revista de Arqueología 24 (3), 11-26.

Igareta, A.; E. Erostarbe \& F. Chechi. (2020). El edificio Casa Natal de Domingo Faustino Sarmiento: un caso de arquitectura doméstica colonial en San Juan, Argentina. Anales de Investigación en Arquitectura 10 (1), 47-64.

Inouye, D. (2007). Role of Pollinators. En Asher Levin, S. (editor) Encyclopedia of Biodiversity, [pp. 1-9]. https://d oi.org/10.1016/B0-12-226865-2/00348-5

Lacoste, P., Premat, E., Castro, A., Soto N. \& Aranda, M. (2012). Tapias y tapiales en Cuyo y Chile (Siglos XVI-XIX). Apuntes, 25 (2), 182-199.

Larraín, N. (1906). El país de Cuyo - Relación histórica hasta 1872. Imprenta de Juan Alsina.

Lugones, L. (1910). Historia de Sarmiento. Buenos Aires. Consejo Nacional de Educación

Manzini M, L. (2011). Las viviendas del siglo XIX en Santiago de Chile y la región de Cuyo en Argentina. Universum (Talca), 26(2), 165-186. doi: https://dx.doi.org/10.4067/S0718-23762011000200009

Miranda, O. (2015). El riego en la provincia de San Juan, Argentina: su dinámica institucional en los últimos dos siglos. Agricultura, sociedad y desarrollo, 12 (3), [385-408]. http://www.scielo.org.mx/scielo.php?script=sci_arttext\& pid=S1870-54722015000300006\&lng=es\&tlng=es 
Nadal Mora, V. (1957). Sobre realización de obras en la casa de Sarmiento. Informe Expediente 52084/56. Comisión Nacional de Monumentos, de Lugares y de Bienes Históricos

Plana, M. R. (2013). Casa Natal de Sarmiento. La vida doméstica del prócer. En Patrimonio Argentino, Casas históricas, Villas y Mansiones (Vol 08, pp. 44-49). Clarín Arquitectura.

Ponte, J. (2006) De los caciques del agua a la Mendoza de las acequias. Cinco siglos de historia de acequias, zanjones y molinos. Instituto de Ciencias Humanas, Sociales y Ambientales. Ciudad y Territorio / CONICET

República Argentina (1872). Primer Censo de la República Argentina verificado en los días 15, 16 y 17 de Setiembre de 1869, bajo la dirección de Diego G. de la Fuente. Superintendencia del censo.

República Argentina (1898). Segundo Censo de la República Argentina mayo 10 de 1895 decretado en la administración del Dr. Saenz Peña, verificado en la del Dr. Uriburu. Población, Tomo II.

Roitman, D. (1996). San Juan: la ciudad y el oasis. Fundación UNSJ (EFU).

Sarmiento, D. ([1850] 1927). Recuerdos de provincia. Biblioteca Argentina. Librería "La Facultad"

Schávelzon, D. (2019). Manual de arqueología urbana II. Métodos y técnicas para excavar basurales. El caso del Bajo Belgrano. Instituto de Arte Americano e Investigaciones Estéticas. Centro de Arqueología Urbana.

Senatore, M. X. (2007). Arqueología histórica, y estructuración social. Perspectiva teóricometodológica. En Arqueologia e Historia en la Colonia Española de Floridablanca. Patagonia-siglo XVIII (pp. 57-79). Editorial Teseo.

Sentagne, M. E., Solera, E., Roses, M. E. \& Laciar, M. (2010). La imagen moderna de la ciudad de San Juan. VI Jornadas de Sociología de la UNLP. Universidad Nacional de La Plata. Facultad de Humanidades y Ciencias de la Educación. Departamento de Sociología, La Plata.

Silva, B. (julio, 1997). Las dimensiones urbanas. Los patrones coloniales y decimonónicos. $49^{\circ}$ Congreso Internacional de Americanistas. Simposio: Historia Urbana de las Américas (HIST 16). Pontificia Universidad de Católica de Ecuador. Quito.

Taboada, C. (2016). Montículos arqueológicos, actividades y modos de habitar. Vivienda y uso del espacio doméstico en Santiago del Estero (tierras bajas de Argentina). Arqueologia de la Arquitectura, (13), e040. doi: http://dx.d oi.org/10.3989/arq.arqt.2016.003

Videla, H. (1956). Retablo sanjuanino. Ediciones Péuser

\section{Notas}

* Licenciada en Antropología (1999) y Doctora en Ciencias Naturales (2008), Facultad de Ciencias Naturales y Museo, Universidad Nacional de La Plata. Investigadora Asistente CONICET - Equipo de Arqueología Histórica HiTePAC, Facultad de Arquitectura y Urbanismo, UNLP. Curadora de colecciones División Arqueología, Museo de La Plata.

** Arquitecta (2015), Facultad de Arquitectura y Urbanismo, Universidad Nacional de La Plata. Equipo de Arqueología Histórica HiTePAC, FAU, UNLP. Ayudante de Curso Ad-Honorem Cátedra Producción de Obras Cremaschi Barandiarán.

1 La publicación del Primer Censo Nacional del año 1869 incluye un breve detalle de censos provinciales y municipales previos; en él se indica que un relevamiento poblacional realizado en el departamento capital de San Juan en 1866 registró 8516 habitantes; resulta lógico suponer que más de medio siglo antes esa cantidad era aún menor, al igual que la superficie ocupada dentro del casco urbano.

2 Para el cálculo en varas se utilizó la equivalencia 1 vara $=0.86 \mathrm{~m}$, tomando como referencia la medida más utilizada en el actual territorio argentino durante el periodo colonial (Silva 1997). A fin de facilitar la lectura del texto y dado que las potenciales discrepancias derivadas del uso de varas de otras longitudes no afectan el sentido general de la propuesta, todas las medidas en metros y varas se redondearán de acuerdo a los decimales.

3 En 1858 Carlos Lepere realiza uno de los primeros planos que se conocen de la ciudad; en él, la manzana que nos ocupa presenta ya las dimensiones aproximadas que mantiene en la actualidad. (Copia del plano incluida en Gray de Cerdán 1971:24)

4 Se ha comprobado arqueológicamente que al momento de fundarse San Juan existía ya en la región una infraestructura hidráulica de acequias y canales prehispánicos, y se ha estimado que la instalación ibérica aprovechó tal sistema para el desarrollo de la nueva ciudad (Damiani y García 2011). 
ana Igareta*, et al. Abordaje aroueológico del sitio Casa Natal Sarmiento (San Juan, Argentina) co...

5 También la ciudad de Mendoza posee un sistema semejante de acequias de origen colonial cuyas características sí han sido extensamente estudiadas y analizadas (e.g. Ponte 2006).

6 La Blastophaga psenes, especie de avispa responsable de la polinización de Ficus carica y Ficus palmata fue introducida en California en 1899 (Inouye 2007).

7 Trabajos arqueológicos desarrollados en otros sitios del país han explorado cómo la participación de esclavos africanos en tareas constructivas determinó rasgos de la arquitectura local (Igareta y Chechi 2020)

8 En el año 1922 Arturo Rossy Malbert realiza un plano y dos cortes del edificio para el Ministerio de Obras Públicas (Archivo CNMLyBH); en dichas imágenes se registra por primera vez la menciona discontinuidad entre las habitaciones de la esquina sureste.

9 Las Actas del Cabildo de la ciudad de San Juan registran desde el siglo XVI y hasta su disolución en 1824 constantes quejas de los vecinos por la obstrucción de las acequias de la ciudad con basura, pero sin que en los documentos se indique si dicha basura proviene del descarte doméstico intencional de los vecinos o de restos de origen orgánico (plantas y animales) que son naturalmente arrastrados por el agua. 